\title{
An Analysis of Errors in Written English Sentences: A Case Study of Thai EFL Students
}

\author{
Kanyakorn Sermsook ${ }^{1}$, Jiraporn Liamnimitr ${ }^{1}$ \& Rattaneekorn Pochakorn ${ }^{1}$ \\ ${ }^{1}$ Department of English for International Communication, Rajamangala University of Technology Srivijaya, \\ Nakhon Si Thammarat, Thailand \\ Correspondence: Kanyakorn Sermsook, Department of English for International Communication, Rajamangala \\ University of Technology Srivijaya, Nakhon Si Thammarat, 80110, Thailand. Tel: 6681-959-7387. E-mail: \\ psuratchawadee@yahoo.com
}

Received: December 28, 2016 Accepted: February 6, 2017 Online Published: February 8, 2017

doi: 10.5539/elt.v10n3p101

URL: http://doi.org/10.5539/elt.v10n3p101

\begin{abstract}
The purposes of the present study were to examine the language errors in a writing of English major students in a Thai university and to explore the sources of the errors. This study focused mainly on sentences because the researcher found that errors in Thai EFL students' sentence construction may lead to miscommunication. 104 pieces of writing written by 26 second-year English major students who enrolled in the Writing II course were collected and analyzed. Results showed that the most frequently committed errors were punctuation, articles, subject-verb agreement, spelling, capitalization, and fragment, respectively. Interlingual interference, intralingual interference, limited knowledge of English grammar and vocabulary, and carelessness of the students were found to be the major sources of the errors. It is suggested that intensive knowledge of English grammar and vocabulary be taught to Thai EFL students. Moreover, the negative transfer of students' first language should be taken into account in English writing classes. This finding also implies that explicit feedback on students' writing errors is genuinely needed.
\end{abstract}

Keywords: English sentence, error, error analysis, writing

\section{Introduction}

\subsection{Background of the Study}

Writing in English has been perceived as the most difficult skill among the four skills of English (Hengwichitkul, 2009; Watcharapunyawong \& Usaha, 2013; Rattanadilok Na Phuket \& Othman, 2015). Even a native speaker fails to write a good piece of writing (Kukurs, 2012). It is, consequently, a very hard task for EFL learners, and it is unavoidable to find errors made by this group of learners since they have a limited chance to write in English. The following sentences written by EFL learners illustrate the difficulties they have encountered.

- She is smiles.

- I see beautiful flowers in garden.

- sara is happy.

- You stick an F.
- There have many trees on a hill. - Everybody love her.

- She has happy.

- It a big house.

- I watch TV 10 o'clock.
- The eggs is cooked.

- I watching a movie.

- Jack is a man diligent.

The above sentences demonstrate a lot of misuses of English grammatical rules which result in grammatically incorrect sentences. Some sentences cannot convey what the writers would like to express. The errors in each sentence reduce the effectiveness of the learners' written sentences.

A number of research studies, as a result, have been conducted both to find out causes of writing problems and to help EFL learners overcome difficulties in their writing. For instance, some studies try to identify types of errors in learners'various types of writing, including sentences, paragraphs, essays, and abstracts, and categorize those errors, so they can be accurately corrected (Huang, 2006; Hengwichitkul, 2006; Jenwitheesuk, 2009; Bumroongthai, 2011; Lui, 2013; Runkati, 2013; Zheng \& Park, 2013; Rattanadilok Na Phuket \& Othman, 2015). Some studies attempt to examine sources of errors since knowing the sources that lead to learners' making of the errors is an effective way to help reduce errors (Penny, 2001; Bennui, 2008; Heydari \& Bagheri, 2012; Watcharapunyawong \& Usaha, 2013; Hinnon, 2014). Furthermore, a considerable number of studies employ 
some approaches to improve learners' writing skill (Presada \& Bradea, 2014; Zafar, 2016).

\subsection{Statement of the Problem}

Some scholars (Corder, 1967; James, 1998) point out that errors made by learners are very significant as they are the indicators of how learners acquire the langauge. According to Corder (1967), errors made by learners are beneficial to teachers, learners, as well as researchers. For teachers, errors are evidence of learners' progress of the language learning. Teachers can refer to it in order to help improve learners' writing skill. For learners, errors can be served as resources for their language learning. Lastly, errors provide evidence to researchers on how learners learn and acquire the language.

To assist these learners, Corder (1967), James (1998), Nonkokhetkong (2013), Hinnon (2014), and Rattanadilok $\mathrm{Na}$ Phuket and Othman (2015) assert that the analysis of errors found in learners' pieces of writing can be very helpful. Some scholars employed Error Analysis (EA), one of the famous methods in their writing classes to improve students' writing performance. Presada and Badea (2014), for example, analyzed the causes of errors made by students in their translation classes and asserted that this method could help them sort out the real problems. They confirmed that Error Analysis (EA) could lessen the number of errors in their students' work. Later, Zafar (2016) states that Error Analysis (EA) is an effective tool to improve her Business students' writing ability after a two-month remedial writing course.

Having learned the advantage of Error Analysis (EA), the researcher believes that this approach could be helpful for her students' writing improvement. Since for a period of time as a teacher teaching students to write in English for their successful communication, the researcher found that English sentences written by Thai EFL students contained various types of errors, such as wrong word choice, subject-verb disagreement, misspelling, wrong use of tenses and punctuation marks. Some of these errors may lead to misunderstanding in cross-cultural communication. For example, "Home make give I happy." which was a sentence written by one of the students who enrolled in the Writing II course was ineffective due to the student's weakness in English. According to a native speaker, this sentence failed to convey a real meaning which the writer intended to mean that his house made him happy.

Hence, the researcher would like to analyze errors in English sentences written by Thai EFL students. The study chose to focus on sentences because they are the small comprehensible units of language forms that students can produce for their effective written communication. These findings may result in a more appropriate lesson plan and more effective teaching materials and teaching methods which can contribute to Thai EFL students' writing improvement. More importantly, it is hoped that the findings arisen from this study will help both teachers and students in other writing classes to achieve a standard of producing pieces of writing.

\section{Literature Review}

\subsection{Error Analysis}

For decades, Error Analysis (EA) has received a great deal of interest from a number of scholars in the field of second language acquisition. The following are the definitions of Error Analysis (EA) given by some of the scholars.

Dulay, Burt and Krashen (1982) state that the analysis of errors is the method to analyze errors made by EFL and ESL learners when they learn a language. Not only can it help reveal the strategies used by learners to learn a language, it also assists teachers as well as other concerning people to know what difficulties learners encounter in order to improve their teaching.

James (1998) proposes that Error Analysis (EA) is the analysis of learners' errors by comparing what the learners have learned with what they lack. It also deals with giving the explanation of the errors in order to accurately reduce them.

Another definition of Error Analysis (EA) given by Crystal (1999) is the study of language learners' language forms which deviate from those of the target language.

According to Corder (1974 cited in Mungungu, 2010), Error Analysis (EA) has two objectives. One is theoretical objective which concerns what and how learners learn a language. The other is the practical one which concerns how to help learners learn a language by making use of the knowledge they have already had. Corder (1974 cited in Mungungu, 2010), hence, asserts that Error Analysis (EA) is useful. He also proposes the five-stage process of Error Analysis (EA) which consists of (1) the collection of errors, (2) the identification of errors, (3) the description of errors, (4) the explanation of errors, and (5) the evaluation of errors (Corder, 1974 cited in Wu \& Garza, 2014). 
Another scholar, Hinnon (2014) also confirms that Error Analysis (EA) is beneficial after her long period of study of literature related to Error Analysis (EA). She mentions that Error Analysis (EA) can let teachers prepare accurate and precise teachings which are suitable for their students.

In short, Error Analysis (EA) is the study of language forms deviating from the standard of the target language which occurs during learners' language learning. The analysis of errors helps reveal the types and sources of errors which can lead to an accurate way and less time consumption to reduce errors made by learners.

\subsection{Classification of Errors}

Errors found in ESL and EFL learners' pieces of writing are analyzed and categorized into various categories.

Errors are categorized according to their features by Dulay, Burt and Krashen (1982) into six different categories: omission of grammatical morphemes, double marking of semantic features, use of irregular rules, use of wrong word forms, alternating use of two or more forms, and misordering.

In the late 1990s, James (1998) proposes five categories of errors which include grammatical errors (adjectives, adverbs, articles, nouns, possession, pronouns, prepositions and verbs), substance errors (capitalization, punctuation and spelling), lexical errors (word formation and word selection), syntactic errors (coordination/ subordination, sentence structure and ordering), and semantic errors (ambiguous communication and miscommunication).

In another study by Hengwichitkul (2006), errors were analyzed at the sentential level. All of the errors were classified as subject-verb agreement, tenses, parts of speech, participial phrases, relative clauses, passive voice, parallel structure, punctuation, run-ons and fragments.

Likewise, Runkati (2013) categorized the errors found in her study into two main types. The former type dealt with errors at the sentential level which were fragments, run-ons, subject-verb agreement, word order, tenses, capital letters and punctuation. The latter one was errors at the word level, such as articles, prepositions, word choices, nouns and numbers.

As the present study focused on errors in English sentences, the analysis of errors found at the sentential level and the word level was adopted. The one regarding sentential level errors included fragments, subject-verb agreement, word orders, tenses, capitalization and punctuation. The other concerning errors at the word level were articles, prepositions, word choices, nouns, pronouns and verbs. Other kinds of analysis, for example, addition and omission were also referred to as sub-categories of the sentential level errors and the word level errors.

\subsection{Sources of Errors}

A number of scholars propose about the sources of errors made by language learners as follows:

Richards (1974), for instance, states that two major sources of errors are interlingual errors and intralingual errors. The first one refers to errors caused when learners wrongly use the rules of their first language when they produce sentences of the target language. The second errors are caused during learners' language learning process. The errors include overgeneralization, false analogy, etc.

James (1998) proposes that there are four sources of errors which are interlingual errors, intralingual errors, communication strategy-based errors, and induced errors.

Based on her study, Penny (2001) concludes that there are two major sources of errors: interlingual transfer and intralingual transfer. Likewise, Heydari and Bagheri (2012) also state that interlingual interference and intralingual interference are the two sources of errors committed by EFL and ESL learners.

In Thailand, a considerable number of scholars also carried out the study to explore the sources of errors.

Kaweera (2013), for example, concludes that there are two main sources of errors, namely interlingual interference and intralingual interference. The first one is a negative transfer of learners' first language. The other one involves errors caused by learners' incomplete knowledge of the target language. Later, Runkati (2013) and Rattanadilok Na Phuket and Othman (2015) propose the two sources causing errors which are interlingual interference and intralingual interference.

After studying and analyzing the research about errors committed by Thai EFL learners, another Thai scholar, Hinnon (2014) differently proposes that there are three sources of errors: Negative transfer of the mother tongue, limited knowledge of the target language, and the difference between words and sentence structures of the mother tongue and those of the target language.

In summary, two major sources leading to errors made by EFL amd ESL learners are interlingual interference 
and intralingual interference.

\subsection{Previous Studies}

As mentioned above that errors made by learners can be used to assist learners to write better, Error Analysis (EA) which is the process to analyze learners' errors systematically has gained a great deal of interest from many scholars and researchers. Error Analysis (EA) was employed to help both EFL and ESL learners improve their writing. Zheng and Park (2013), for instance, analyzed the errors found in English essays written by Chinese and Korean students. Results showed that errors made by these two groups of writers were various. They had problems in using articles and punctuation marks, and ordering words. Zheng and Park (2013) mentioned that the negative transfer of the subjects' first language was the major source of the errors. In a similar study of Liu (2013), it was found that the participants who were Chinese learners made the errors when they wrote English sentences. She pointed out that the sources were carelessness and negative influence of the subjects' mother tongue.

The analysis on errors made by ESL learners can be seen in the study of Khansir (2013). He compared and examined the error types found in the written products of ESL and EFL students. He concluded that there were no significant differences between the errors found in the written products of the two groups of the writers. It can be concluded that both ESL and EFL learners faced similar problems in writing. Later, Zafar (2016) conducted an empirical study which used Error Analysis (EA) as a treatment. She first analyzed errors frequently made by her Business students, and verb tenses were found to be the most problematic ones. After a two-month writing training focusing on the accurate use of verb tenses, her students had an apparent improvement.

In Thailand where English has been taught as a foreign language and writing in English is confirmed to be the most difficult skill for Thai learners to master, Error Analysis (EA) has been an attractive approach and has been used by a lot of scholars to improve the writing skill of the Thai learners. Bennui (2008), for example, analyzed errors caused by the transfer of the subjects' mother tongue which was Thai. The findings showed that the Thai language negatively influenced the subjects' writing at all levels including lexical, syntactic and discourse levels. He concluded that the differences between Thai and English should be taught to Thai EFL students. Similarly, in the analysis of English sentences written by Thai undergraduate students, Jenwitheesuk (2009) found that the sentences contained errors, such as determiners, subject-verb agreement, tenses and prepositions. Moreover, Watcharapunyawong and Usaha (2013) studied errors caused by the interference of the first language. Their findings also pointed out that the students' first language had a strong influence on their writing.

Other types of writing, such as paragraphs, essays and abstracts were also analyzed. Bumroongthai (2011) was interested in analyzing errors in English paragraphs. Based on the results, she concluded that the Thai EFL students committed various types of errors regarding English grammar and the paragraph format. Hengwichitkul (2006) analyzed errors in abstracts written by Thai graduate students. It can be concluded from her findings that the differences between Thai and English languages and the complexity of English sentences led to the errors. Rattanadilok Na Phuket and Othman (2015) found many types of errors, for example, tenses, prepositions, word choice and comma errors in narrative essays written by Thai undergraduate students. From the analysis, they stated that the negative transfer of the students' first language was the main cause of the errors.

It can be concluded from the above findings that Thai EFL learners as well as other EFL and ESL learners encounter difficulties when they have to write in English. The major sources of the errors are the negative transfer of learners' first language and their incomplete knowledge of the target language. Other sources, such as learners' carelessness cannot be overlooked. Analyzing learners' errors in written English and seeking for sources of those errors have been proven to be helpful to EFL and ESL learners' writing improvement.

The present study, therefore, was conducted to find errors frequently found in English sentences written by Thai EFL students. Besides, it aimed at examining sources of the errors. Apart from studying previous studies related to sources of errors, this study employed the questionnaire and interview so as to get some in-depth information lying behind the errors. Hopefully, this will raise students' awareness on the errors they made and prevent them from making the errors again.

\section{Method}

\subsection{Research Questions}

The present study aimed at finding the answers to the following questions.

1). What types of errors are frequently found in English sentences written by Thai EFL students?

2). What are the sources of the errors? 


\subsection{Participants}

The participants of the study were 26 second year English major students in a Thai university. They were two males and 24 females whose age ranged from 20 to 22 years old. All of them have learned English as a foreign language for at least seven years.

\subsection{Instruments}

To obtain the information regarding errors frequently made by the participants, 104 pieces of their written work were collected. To seek for sources of errors, questionnaires and individual/ group interview were employed. Previous studies related to sources of errors in writing were also analyzed.

\subsection{Data Collection}

The following three stages were performed to collect data of the present study.

Stage 1: All of the 104 pieces of the students' written work were marked by the researcher. Each sentence was examined word by word. Each error was recorded according to its type in an individual error record form.

Stage 2: All of the students were asked to write the sources they thought led to errors made by them into the questionnaire.

Stage 3: Either by a group or individually, each student was interviewed to obtain in-depth information pertaining to sources of errors.

The information obtained from Stage 2 and Stage 3 was later interpreted and analyzed to identify the sources of the errors found in their writing.

\subsection{Data Analysis}

The data analysis procedure consisted of two stages according to the purposes of the study.

Stage 1: All of the collected errors were analyzed and labeled according to the types of errors to get the frequency and the percentage. Then each error type was classified into two main groups: The sentential level errors and the word level errors. Additionally, the characteristics of the errors, such as omission and addition were identified.

Stage 2: To seek for major sources of the errors, the information from the questionnaires and the interview was interpreted and analyzed. Moreover, previous research pertaining to sources of errors was studied.

\section{Results and Discussion}

The results and discussion of the study are presented in accordance with the two research questions proposed earlier.

\subsection{Errors Frequently Found in English Sentences Written by Thai EFL Students}

After the analysis of errors, seventeen types of errors were found in English sentences written by Thai EFL students. The errors at the sentential level comprised punctuation, subject-verb agreement, capitalization, fragments, tenses, and word order. The ones at the word level were articles, nouns, pronouns, verbs, prepositions, adjectives, literal translation from the Thai language, parts of speech, word choices, spelling, and transition words. The table below demonstrated types, frequency, percentage and rank of the errors. 
Table 1. Types, frequency, percentage, and rank of the errors found in the English sentences

\begin{tabular}{lccc}
\hline Types of Errors & Frequency & Percentage & Rank \\
\hline Errors at the sentential level & & & \\
Tense & 10 & 3.38 & 13 \\
Subject-verb agreement & 35 & 11.82 & 3 \\
Fragment & 23 & 7.77 & 6 \\
Word order & 5 & 1.69 & 14 \\
Punctuation & 42 & 14.19 & 1 \\
Capitalization & 24 & 8.12 & 5 \\
Errors at the word level & & & 2 \\
Articles & 39 & 4.18 & 10 \\
Nouns & 12 & 4.05 & 10 \\
Pronouns & 12 & 5.74 & 7 \\
Verbs & 17 & 5.07 & 8 \\
Prepositions & 15 & 1.01 & 15 \\
Adjectives & 3 & 4.73 & 9 \\
Literal translation from & 14 & 1.01 & 15 \\
Parts of speech & 3 & 3.72 & 12 \\
Word choices & 11 & 9.80 & 4 \\
Spelling & 29 & 0.67 & 17 \\
Transition words & 2 & $\mathbf{1 0 0}$ & \\
Total & $\mathbf{2 9 6}$ & & \\
\hline
\end{tabular}

As shown in Table 1, punctuation was the most frequently-made error type (14.19\%). Other error types were articles $(13.18 \%)$, subject-verb agreement (11.82\%), spelling (9.8\%), capitalization $(8.12 \%)$, fragments $(7.77 \%)$, verbs $(5.74 \%)$, prepositions $(5.07 \%)$, literal translation from Thai $(4.73 \%)$, nouns and pronouns $(4.05 \%)$, word choices $(3.72 \%)$, tense $(3.38 \%)$, word order $(1.69 \%)$, adjectives and parts of speech $(1.01 \%)$, and transition words $(0.67 \%)$, respectively.

A deeper analysis of the errors revealed that the six types of errors found to be the greatest difficulties of the participants were punctuation marks, articles, subject-verb agreement, spelling, capitalization, and fragments, respectively.

\subsubsection{Punctuation Marks}

Based on the collected data and the analysis, punctuation marks were the most frequently committed errors. The errors can be divided into two categories according to their features: omission and addition. Punctuation marks which were found to be the most problematic were comma (,) and period (.). A deeper analysis revealed that the different uses of these two punctuation marks between Thai and English were the causes of the errors. A clear explanation can be seen from the following examples.

Example 1: Later I watched TV. (Later, I watched TV.)

Example 2: When I was young I lived in a big house. (When I was young, I lived in a big house.)

In the above sentences, a comma was omitted. In these two cases, it can be explained that commas are not used after a transition word or a subordinate clause in a Thai sentence, so the writers with their incomplete knowledge of English might apply the Thai rule when they wrote these two English sentences.

Example 3: You can speak English if you follow the three steps

(You can speak English if you follow the three steps.)

The sentence in Example 3 has no period. This phenomenon can be explained that in Thai, a period is not used to signal the end of a sentence.

Example 4: It has three bedrooms, three bathrooms. (It has three bedrooms and three bathrooms.)

The sentence in Example 4 showed the addition of a comma when it is not needed. The writer may wrongly refer to the rule of English when writing this sentence. Actually, in this case 'and' is needed to make a complete sentence. 


\subsubsection{Articles}

Articles were found to be errors in the second rank made by the participants. This group of Thai EFL students got confused with the use of $a$, an, the, and zero article. The errors found can also be grouped into omission and addition.

Example 5: It has living room. (It has a living room.)

Example 6: She is friendly person. (She is a friendly person.)

The two examples above present the omission of the articles from a sentence. All of the given examples may be due to Thai language interference since there are no articles in the linguistic rule of the Thai language.

The following two examples illustrate the addition of articles when they are not necessary.

Example 7: I have a dinner. (I have dinner.)

Example 8: I go to the bed. (I go to bed.)

Based on the above two sentences, it can be explained that the writers might wrongly apply the rule of the target language. This can be the results of the intralingual interference.

\subsubsection{Subject-verb Agreement}

The third rank error is the subject-verb agreement which is a common error found in Thai EFL students' writing (Jenwitheesuk, 2009; Bumroongthai, 2011; Runkati, 2013; Rattanadilok Na Phuket \& Othman, 2015). It is an error frequently made by other EFL students from other different countries (Huang, 2006; Wu \& Garza, 2014). The following examples demonstrate the writers' confusion about the rules of the subject-verb agreement.

Example 9: I gets up. (I get up.)

Example 10: She speak politely. (She speaks politely.)

The possible explanation for Example 9 is the faulty application of rules. The writer might think that 'I' is one person which is singular, so he/she added $s$ after the verb. In contrast, the writer of Example 10 may be influenced by the first language. In Thai, the form of verbs remains unchanged with any subjects. Therefore, the writer did not change the form of the verb.

\subsubsection{Spelling}

The majority of the spelling errors committed by the participants were occurred by using an incorrect letter, omitting a letter, or adding a letter when unnecessary as shown in the sample sentences below.

Example 11: I did homeword. (I did homework.)

The error in Example 11 occurred by using an incorrect letter.

Example 12: It has tree bedrooms. (It has three bedrooms.)

The above example contains the error which occurred by omitting a letter.

Example 13: My writting is bad. (My writing is bad.)

Adding an unnecessary letter caused the error in Example 13.

A data analysis revealed that the cause of the above errors was the writers' limited knowledge of English vocabulary. Another possible cause derived from the interview and questionnaires was their carelessness. From the sample sentences, it is noticeable that the sentence in Example 12 fails to convey the writer's real intention in that he/ she wanted to tell a reader about the number of the bedrooms, but with the absence of the letter ' $h$ ', it can be understood that the writer would like to talk about the material which the bedrooms were made of. Another error in Example 13 may lead to the conclusion that the writer got confused with, and misused the rule of V-ing form which indicates that doubling the last letter of a verb before -ing is needed for one-syllable words (Vince, 2010). Therefore, this writer added another letter ' $t$ ' before-ing to change 'write' to 'writing'.

\subsubsection{Capitalization}

Example 14: on saturday

(on Saturday)

Example 15: the house is large. (The house is large.)

It can be explained that the cause of the errors is the interference of the Thai language since there is no rule of capitalization in a Thai context. The writers, moreover, had inadequate knowledge of the English rule in that the first letter of specific nouns and the first letter of a sentence must be capitalized. These two causes led to the occurrence of the errors. 


\subsubsection{Fragments}

This type of errors can be divided into two groups: no verb and no subject. The errors occurred due to the Thai language interference. The following examples can clearly illustrate the problem.

Example 16: He stressed. (He is stressed.)

The sentence in Example 16 has no verb because the writer literally translated a Thai sentence, 'Khao Khriad (เขาเครียด) into English. Another example of a fragment is shown in the example below.

Example 17: Molly is very kind. Make everyone like her. (She makes everyone like her.)

The underlined sentence contains no subject which is also caused by the literal translation of Thai into English. As can be seen in Example 17, the fragment is supposed to be the sentence which continues from the first sentence. In Thai, the subject of the second sentence can be omitted without causing any errors, but in English, the omission of a subject results in an incomplete sentence, and may fail to convey the full meaning of a sentence.

\subsection{Sources of the Errors}

The information gained from the questionnaires, the interview, as well as related literature revealed the four major sources of the errors as follows:

4.2.1 Interlingual interference is the major source causing the most errors, 206 errors out of 296 errors. This is because the students always thought in their first language when they produced written English sentences. Interlingual interference is also the main cause of errors found in other Thai EFL learners' writing (Bennui, 2008; Watcharapunyawong \& Usaha, 2013; Rattanadilok Na Phuket \& Othman, 2015). Interestingly, some of the participants from this study claimed that the Thai linguistic rules which were similar to those of English could help them learn English better. For instance, they did not have problems in spelling English words which were pronounced like Thai words, such as วีดีโอ-video, บอล-ball, แจ็คเก็ต-jacket, etc. It can be concluded that pointing out both differences and similarities between the students' first language and the target language should be considered in the writing classes.

4.2.2 Intralingual interference is the learners' confusion of using the target language. Their knowledge of the target language is incomplete, so they combined the knowledge of Thai with that of English.

4.2.3 Limited knowledge of English grammar and vocabulary is another crucial source of the participants' errors. Very limited knowledge of English grammar and vocabulary leads the writers to commit errors (Silva, 1993; Olsen, 1999; Weigle, 2002). The data from the interview confirm that Thai EFL students' knowledge of English grammar and vocabulary need to be improved. The participants of the study expressed that their grammar and vocabulary knowledge of English was inadequate to make a good piece of writing. From the researcher's point of view, to successfully help EFL or ESL learners write better in English, complete grammar and vocabulary knowledge of the target language is absolutely needed since a writer with the deficiency of that knowledge tends to make more errors when writing in the target language.

4.2.4 Carelessness: According to the information from the interview and the questionnaires, though carelessness seemed to be the source of the least errors, it cannot be overlooked. Raising EFL writers' awareness of the disadvantage of carelessness may help reduce errors in their writing.

Previous studies indicate that interlingual interference and intralingual interference are the two sources of errors found in EFL and ESL learners' pieces of writing. The findings of this study also agree with the mentioned conclusion. The present study, in addition, would like to draw attention to other sources that may lead to serious errors. Very limited knowledge of English grammar and vocabulary as well as learners' carelessness is other sources that cannot be underestimated. EFL learners' awareness of the two mentioned sources should be raised in order to reduce any unexpected errors.

\section{Pedagogical Implication}

The findings from this study provide some pedagogical implications. First, errors made by EFL learners are valuable indications of learners' language learning progress. Moreover, they can reveal real problems learners have in their writing. Teachers can utilize these errors to improve learners' writing performance. Second, learners' first language plays a vital role in their language learning since it can positively and negatively influence their writing behaviours. Pointing out the differences and the similarities between the target language and learner's first language should be taken into consideration. Next, the findings imply that the knowledge of grammar and vocabulary of the target language is needed for a comprehensible piece of writing. Based on this research, students' deficiency of the target language knowledge seems to be the major source which obstructs the 
students' effectiveness in writing English sentences. Therefore, properly-prepared grammar and vocabulary lessons in accordance with frequently found errors can be effective in improving students' writing. Lastly, students' carelessness should be discussed in English writing classes for a more effective piece of writing made by students.

\section{Conclusion}

The present study aimed at analyzing errors committed by Thai EFL students when they produced pieces of writing in English, and to seek for the sources that lead to the errors. The findings showed that the students made different types of errors due to four sources: interlingual interference, intralingual inference, limited knowledge of English grammar and vocabulary, and their carelessness. From these findings, limited knowledge of the target language may be the major source leading to other sources since having very limited knowledge of English, the students turned to rely on their first language. This can result in errors that could cause written miscommunication. Teachers, hence, should consider the differences between vocabulary and grammar knowledge of English and those of students' first language. Last, but not least, the researcher would like to emphasize that errors found in EFL students' writing are not wrong, but useful tools to help EFL students make fewer errors and write better in English.

\section{Acknowledgments}

The authors gratefully thank Rajamangala University of Technology Srivijaya for the financial support. Without this support, the research would not have been completed. Our sincere thanks are also due to the participants in the study and the reviewers of the article.

\section{References}

Bennui, P. (2008). A study of L1 interference in the writing of Thai EFL students. Malaysian Journal of ELT Research, 4, 72-102.

Bumroongthai, G. (2011). An error analysis in English paragragh writing by students of the faculty of liberal arts, Rajamangala University of Technology Phra Nakhon. (Research report). Rajamangala University of Technology Phra Nakhon, Bangkok, Thailand.

Corder, S. P. (1967). The significance of learner's errors. International Review of Applied Linguistics in Language Teaching, 5(4), 161-170. https://doi.org/10.1515/iral.1967.5.1-4.161

Crystal, D. (1999). The penguin dictionary of language. London: Penguin.

Dulay, H. C., Burt, M.K., \& Krashen, S.D. (1982). Language two. New York: Oxford University Press.

Hengwichitkul, L. (2006). An analysis of errors in English abstracts translated by Thai university graduate students. (Unpublished master's thesis). Srinakharinwirot University, Bangkok, Thailand.

Heydari, P. \& Bagheri, M. S. (2012). Error analysis: Sources of L2 learners' errors. Theory and Practice in Language Studies, 2(8), 1583-1589. https://doi.org/10.4303/tpls.2.8.1583-1589

Hinnon, A. (2004). Common errors in English writing and suggested solutions of Thai university students. มนุษยศาสตร์ สังคมศาสตร์, 31(2), 165-180.

Huang, S. J. (2006). A case study of EFL students' writing errors on a web-based writing program. Paper presented at International Conference \& Workshop on TEFL and Applied Linguistics, Ming Chuan University, China.

James, C. (1998). Errors in language learning and use: Exploring error analysis. New York: Routledge.

Jenwitheesuk, T. (2009). A study of persisted syntactic errors in writing of the $3^{\text {rd }}$ year students of English for international communication program. Paper presented at International Conference on the Role of University in Hands-on Education, Rajamangala University of Technology Lanna, Thailand.

Kaweera, Ch. (2013). Writing error: A review of interlingual and intralingual interference in EFL context. English Language Teaching, 6(7), 9-18. http://dx.doi.org/10.5539/elt.v6n7p9

Khansir, A. A. (2013). Error analysis and second language writing. Theory and Practice in Language Studies, 3(2), 363-370. https://doi.org/10.4304/tpls.3.2.363-370

Kukurs, R. (2012). 3 killers tips on how to write in English like a native speaker. http://www.englishharmony.com/write-like-a-nativee-speaker/.

Liu, M. (2013). An investigation of syntactic errors in Chinese undergraduate EFL learners' compositions: A cohort study. International Journal of Applied Linguistics and English Literature, 2, 182-191. 
https://doi.org/10.7575/aiac.ijalel.v.2n.4p.182

Mungungu, S. S. (2010). Error analysis: Investigating the writing of ESL Namibian learners. (Unpublished master's thesis). University of South Africa, Pretoria, South Africa.

Nonkukhetkhong, K. (2013). Grammatical error analysis of the first year English major students, Udon Thani Rajabhat University. Paper presented at the Asian Conference on Language 2013, Osaka, Japan.

Olshen, S. (1999). Errors and compensatory strategies: A study of grammar and vocabulary in texts written by Norwegian learners of English. System, 27, 191-205. http://dx.doi.org/10.1016/S0346-251X(99)00016-0

Penny, W. K. (2001). An analysis of student error patterns in written English: Suggested teaching procedure to help. (Unpublished master's thesis). University of Birmingham, Birmingham, England.

Presada, D., \& Badea, M. (2014). The effectiveness of error analysis in translation classes. A pilot study. Porta Linguarum, 22, 49-59.

Rattanadilok Na Phuket, P., \& Othman, N. B. (2015). Understanding EFL students' errors in writing. Journal of Education and Practice, 6(32), 99-106.

Richards, J. C. (1974). Error analysis: Perspectives on second language acquisition. London: Longman.

Runkati, K. (2013). Organizational patterns and common mistakes in English research abstracts. (Unpublished master's thesis). Prince of Songkla University, Songkhla, Thailand.

Silva, T. (1993). Toward an understanding of the distinct nature of L2 writing: The ESL research and its implications. TESOL Quarterly, 27, 657-677. http://dx.doi.org/10.2307/3587400

Vince, M. (2010). Elementary practice (3rd ed.). London: Macmillan.

Watcharapunyawong, S., \& Usaha, S. (2013). Thai EFL students' writing errors in different text types: The interference of the first language. English Language Teaching, 6(1), 67-78. http://dx.doi.org/10.5539/elt.v6n1p67

Weigle, S. C. (2002). Assessing writing. Cambridge: Cambridge University Press. http://dx.doi.org/10.1016/S1060-3743(02)00084-X

Wu, H., \& Garzar, E.V. (2014). Types and attributes of English writing errors in the EFL context-A study of error analysis. Journal of Language Teaching and Research, 5(6), 1256-1262. https://doi.org/10.4304/jltr.5.6.1256-1262

Zafar, A. (2016). Error analysis: A tool to improve English skills of undergraduate students. Procedia-Social and Behavioral Science, 217, 697-705. https://doi.org/10.1016/j.sbspro.2016.02.122

Zheng, C., \& Park, T. (2013). An analysis of errors in English writing made by Chinese and Korean university students. Theory and Practice in Language Studies, 3(8), 1342-1351. https://doi.org/10.4304/tpls.3.8.1342-1351

\section{Copyrights}

Copyright for this article is retained by the author(s), with first publication rights granted to the journal.

This is an open-access article distributed under the terms and conditions of the Creative Commons Attribution license (http://creativecommons.org/licenses/by/4.0/). 